\title{
Temporal-spatial stability of competition in marine boulder fields
}

\author{
David K. A. Barnes* \\ British Antarctic Survey, Natural Environment Research Council, High Cross, Madingley Road, Cambridge CB3 OET, UK
}

\begin{abstract}
Demonstrable examples of marine interference-competition on ecological, and particularly evolutionary, time-scales have been highly confined in space. However, studies of such competition across large-scale space are conversely mere 'snapshots' in time. The current study aimed at measuring interference-competition at multiple scales in space and time. Different aspects of interference-competition were measured in a model community (encrusters of boulder communities, e.g. ascidians, bryozoans, polychaetes and sponges) at 3 tropical, 3 temperate and 2 polar sites at intervals of days, weeks, months and years. The 3 aspects of competition measured - transitivity (hierarchicalness), number of clades involved, prevalence of interspecific encounters - varied nonsignificantly with time (from days to years) but significantly in space (from the tropics to the poles). Thus the strong differences observed in space are robust along ecological time-scales; boulder communities may be highly dynamic at local scales, but overall measures of interference-competition amongst their encrusters seem to vary little within a region. Why low- and high-latitude encrusting communities should differ may be linked to past selection pressures - to survive spatial competition in the more stable warm seas and to be able to recolonise from local ice-scour and regional ice sheets in the high temperate and polar realms. The results of the current study suggest that, despite being 'snapshots', the many point-in-time studies of competition in the literature are likely to be valid on ecological time-scales and thus useful for meta-analyses.
\end{abstract}

KEY WORDS: Hierarchies · Encrusting community · Latitude · Scales

\section{INTRODUCTION}

We know little about how competition changes over time and space, as there have been few studies incorporating many scales of either, let alone both. Most biologists consider that competition is, or has been (Connell 1980), fundamental to the shaping of species, communities and even ecosystems along ecological and evolutionary time-scales. Despite this perceived importance, it is striking that most direct demonstrations of competition have been very small-scale (Connell 1961a, Brown \& Davidson 1979, Schluter 1986). Marine benthic organisms, and even assemblages, and their interactions can, however, persist remarkably well, allowing ecologists a glimpse into historic competition (Taylor \& Wilson 2003). This persistence has enabled investigation of major patterns in cryptic encrusting communities (such as cyclostome and cheilostome bryozoans) over large time-scales. Work on these taxa, spanning Mesozoic to Recent times, has revealed rare and powerful examples of both longterm competition and ecological versus evolutionary success (Lidgard et al. 1993, McKinney 1995, McKinney et al. 1998).

Some models have, however, cast doubt on whether competition is the major explanatory factor for one clade's rise and another's fall (Sepkoski 1996). One of the few sources of data on actual, rather than implied, long-term competition, shows that cheilostomes have consistently won about $66 \%$ of encounters with cyclostomes throughout the last 100 million yr (McKinney 1995). McKinney's (1995) remarkable data does show strong consistency of competitive outcomes over a considerable geological time span, but is restricted to 
one environment (a warm, shallow sea). However, the taxa involved were, and are, not so geographically restricted. Modern data from shallow seas support McKinney's (1995) findings, but results of competition between the same taxa in other environments differ considerably (Fig. 1). In the present study, competition in similar cryptic, encrusting, communities on boulders was investigated across the globe at multiple scales in both time and space.

Typically it has proved difficult to evaluate competition along evolutionary or ecological time-scales, since outcomes depend on geography and little is known about historic patterns in space. One answer is to evaluate patterns in current time across large-scale space (Barnes 2002). However, many biologists are (rightly) critical of point-in-time studies of competition in communities across latitude and longitude in modern times, because such studies are only a 'snap-shot in time' and could have quite different outcomes if measured at other times. Encrusting organism communities of coastal boulder fields represent ideal models as (1) they generally have to compete for a limiting resource (space), (2) spatial encounters, resulting in interactions, are abundant across the globe, and (3) the competitors are sessile and so competitive encounters are easy to observe and interpret. For this reason, such communities have been widely used to test the ecological theory (e.g. Connell 1961a,b, Jackson 1979, Grosberg 1981, McKinney 1995, Barnes 2002). The present study tests the null hypothesis that estimates of (some aspects of) competition (e.g. hierarchicalness) do not change across short ecological time-scales (days, years). Such a hypothesis is proposed because McKinney's (1995) data implies stability of community com-

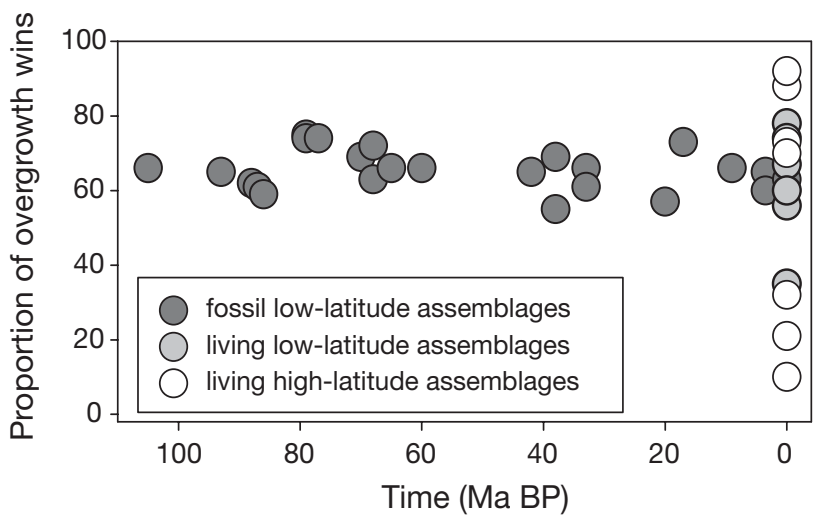

Fig. 1. Comparative success of 2 clades in time and space, showing proportion of wins by cheilostome bryozoans in spatial competition with cyclostome bryozoans. The $y$-axis is proportion of wins by cheilostomes, with each point representing different assemblage; the $x$-axis is millions of years ago before present (Ma BP). Plot adapted from Barnes \& Dick (2000) using fossil data from McKinney (1995) petition in evolutionary time and Tanaka \& Nadakumar's (1994) work has shown outcomes of individual interactions to be stable on ecological time-scales. In the present study, several independent aspects of competition were measured at each of several tropical, temperate and polar sites over time-scales of days, weeks, months and years to try to assess the generality of any temporal-spatial stability found.

\section{MATERIALS AND METHODS}

Study sites and sampling. Aspects of competition for space by cryptic encrusters (ascidians, bryozoans, cnidarians, polychaetes and sponges) were measured at various time intervals in communities encrusting the undersurfaces of coastal boulders. Upper surfaces (exposed to light) were observed to contain few interactions and were generally monopolised by algae. Algae-animal interactions were harder to interpret, and were complicated by light regime; this difficulty was avoided by considering only boulder undersurfaces. This was done at 3 tropical, 3 temperate and 2 polar study sites over the period 1991 to 2004. Of these sites, only 2 (temperate) were in the northern hemisphere: Oban, W Scotland $\left(57^{\circ} \mathrm{N}, 6^{\circ} \mathrm{W}\right)$ and Baltimore, SW Ireland $\left(51^{\circ} \mathrm{N}, 9^{\circ} \mathrm{W}\right)$. The polar sites were Adelaide Island $\left(68^{\circ} \mathrm{S}, 68^{\circ} \mathrm{W}\right)$ and Signy Island $\left(60^{\circ} \mathrm{S}\right.$, $45^{\circ} \mathrm{W}$ ) in the Southern Ocean. The tropical study sites were Andavoka, SW Madagascar $\left(24^{\circ} \mathrm{S}, 43^{\circ} \mathrm{E}\right)$, and Quirimba Island, N Mozambique $\left(16^{\circ} \mathrm{S}, 41^{\circ} \mathrm{E}\right)$ in the Indian Ocean, and NE Bay, Ascension Island $\left(7^{\circ} \mathrm{S}\right.$, $14^{\circ} \mathrm{W}$ ) in the Atlantic, as was the remaining temperate site, Stanley, W Falkland $\left(51^{\circ} \mathrm{S}, 59^{\circ} \mathrm{W}\right)$. In most cases, sampling was undertaken at each of these sites such that 3 replicate samples (10 to $100 \mathrm{~m}$ apart) were collected days, weeks, months and years apart in the same community (Table 1). The longest time range of collections was $11 \mathrm{yr}$ at Signy Island and the shortest was 3 mo in SW Madagascar. Each sample comprised a series of boulders from which 500 interactions were randomly chosen using an overlay non-elastic cloth marked with grid and points. Interactions underlying each point were chosen. After considering of many different potential protocols, it was concluded that the most practical method, with the least potential bias, was to record the interaction closest to each point. At some sites, individual colonisers were typically larger than at others, so this method inevitably lead to some differences in the manner and area in which interactions were gathered. Although this represents a source of error, there is no obvious way in which this would bias the findings. Thus approximately 500 (interactions) $\times 3$ (replicates) $\times 4$ (time periods) $\times 8$ (study sites) 48000 competitive interactions were measured: in 
Table 1. Frequency of sampling at study sites

\begin{tabular}{|lccccc|}
\hline Sites & Days & Weeks & Months & Years & Max. \\
\hline Oban, Scotland & $\checkmark$ & $\checkmark$ & $\checkmark$ & $\checkmark$ & $3 \mathrm{yr}$ \\
SW Ireland & $\checkmark$ & $\checkmark$ & $\checkmark$ & $\checkmark$ & $7 \mathrm{yr}$ \\
Ascension Island, Atlantic & $\checkmark$ & & $\checkmark$ & $\checkmark$ & $3 \mathrm{yr}$ \\
N Mozambique & $\checkmark$ & $\checkmark$ & $\checkmark$ & & 4 mo \\
SW Madagascar & $\checkmark$ & $\checkmark$ & $\checkmark$ & & $3 \mathrm{mo}$ \\
Stanley, Falklands & $\checkmark$ & & $\checkmark$ & $\checkmark$ & $3 \mathrm{yr}$ \\
Signy Island, Antarctica & $\checkmark$ & $\checkmark$ & $\checkmark$ & $\checkmark$ & $11 \mathrm{yr}$ \\
Adelaide Island, Antarctica & $\checkmark$ & $\checkmark$ & $\checkmark$ & $\checkmark$ & $3 \mathrm{yr}$ \\
\hline
\end{tabular}

is known, however, that some organisms (e.g. ascidians) are capable of surviving temporary overgrowth, and regenerate if the overgrowing competitor later recedes (Todd \& Turner 1988). Recent literature suggests that ties (mutual but equal overgrowth, or skeletal build-up but no overgrowth) are stable over time (Sebens 1986, Tanaka \& Nandakumar 1994, author's pers. obs.). Secondly, a species (competitor)-pair matrix was set up comprising a subset of competitors which all encountered each other. Third, community transitivity was estimated for each matrix according to Tanaka \& Nandakumar's (1994) index selected communities (SW Ireland, Ascension Island and Signy Island), 120 interactions were monitored to confirm that the results of interactions did reflect the outcome of competition. Each of these interactions was photographed and re-photographed using a 1:1 macrolens, with only the boulders marked. Of the 120 interactions, only 2 did not agree with the initial assessment of a win, loss or tie at any later time point (up to 2 yr in SW Ireland). In Ascension and Signy Islands, the equivalent values were 1 of 120 and 0 of 120 over a 2 yr period. It is possible that some individuals, that had been overgrown, survived longer than $2 \mathrm{yr}$ and/or were freed by recession of the overgrowing organism. This was probably the case for only a few individuals, especially at the polar localities, in which very few recruits in such communities survive for 2 yr (Barnes \& Arnold 2001) and events that remove the overgrowing organism also remove that which is overgrown (e.g. incidental predation by echinoids or ice-scour: author's pers. obs.). The estimates of competition made here were therefore considered to be meaningful within the time-frame of the present study.

Measurement of competition. In each replicate community, 3 features were estimated: (1) the level of hierarchicalness of competition (generally referred to as transitivity, see Petraitis 1979, Rubin 1982, Tanaka \& Nandakumar 1994): (2) the number of clades (groups of related organisms, e.g. demosponges) involved in competitive interactions: (3) the proportion of competition that was interspecific (as opposed to intraspecific). Estimation of the hierarchical community competition was in 3 stages: first, the outcome of spatial competition for each competitor in each encounter was scored as a win, loss or tie. A win for one competitor (=a loss for the other) was recorded in the case of $>5 \%$ overgrowth, in accordance with the literature (see Barnes 2002 and references therein). It

$$
\begin{gathered}
\mathrm{WI}=\sqrt{\frac{\sum_{i=1}^{\mathrm{n}} \sum_{j=1}^{\mathrm{n}} \mathrm{P}_{i j}[\mathrm{~W}]^{2}}{2}} \quad \mathrm{LI}=\sqrt{\frac{\sum_{i=1}^{\mathrm{n}} \sum_{j=1}^{\mathrm{n}} \mathrm{P}_{i j}[\mathrm{~L}]^{2}}{\frac{\mathrm{n}(\mathrm{n}-1)}{2}}} \\
\mathrm{SI}=\sqrt{\frac{\sum_{i=1}^{\mathrm{n}} \sum_{j=i+1}^{\mathrm{n}} \mathrm{P}_{i j}[\mathrm{~S}]^{2}}{\frac{\mathrm{n}(\mathrm{n}-1)}{2}}}
\end{gathered}
$$

where WI = win index, LI = loss index and SI = tie/ standoff index. The WI index $\mathrm{P}_{i j}[\mathrm{~W}]^{2}$ is the sum-ofsquares of the proportion of wins by each competitor species divided by the total number of encounters of each, whereby 0 represents a network composed entirely of tied outcomes and 1 a hierarchy in which A outcompetes all others, B outcompetes all others apart from A, C outcompetes all others apart from A and B etc. Thus the closer the index is to 1 , the more hierarchical the assemblage. This method of quantification of transitivity is described in detail (with examples) by Tanaka \& Nandakumar (1994) and Barnes (2002).

Although the richness of each clade is typically likely to be higher in the tropics (see e.g. Stehli \& Wells 1971, van Soest 1994, Giangrande \& Licciano 2004, Witman et al. 2004), the total number and identity of major clades present at all sites was similar. It was considered important to measure the number of types (clades) of competitor, as competing with more different (distantly related) organisms typically leads to more determinate outcomes (win/loss as opposed to ties) and thus more serious implications for competition (Jackson 1979, Barnes 2003). The third aspect of competition measured was a comparison of how many encounters were interspecific and how many were intraspecific. Competition in some cryptic environments can mainly occur between individuals in just one clade (e.g. demo- 
sponges), whilst individual encounters at the same sites are mainly interspecific because of high species richness. Furthermore, competition on many bedrock shores is characterised by the presence of a number of clades (barnacles, mussels and polychaetes), but competion within just 1 or 2 species, in each clade, dominate the battle for space.

Statistical analyses. The data for each of the 3 aspects of competition (transitivity, number of taxa involved and prevalence of interspecific encounters) were analysed using a generalised linear model (GLM) ANOVA (MINITAB 13 software). The factors were, region (fixed), sites (random) nested within region, and time (fixed), the interaction terms, region $\times$ time, and site(region) $\times$ time. All 3 aspects of competition were plotted against time for each study site. Regression lines were fitted to this data (mainly to aid visualisation of variance or trends). The slopes of any significant regression lines were compared to zero (Student's $t$-tests).

\section{RESULTS}

Overall transitivity levels in the boulder communities studied varied from very high (strict hierarchies) to moderately low (networks). Levels of transitivity varied little and non-significantly between time periods but significantly between the study sites and regions (Table 2a). At each study site, regressions with time (from days to years between sampling periods) were all non-significantly different from zero (Fig. 2). Thus the hypothesis that transitivity would not change with time could not be rejected on a days-to-years timescale for coastal boulder communities.

The taxa involved in competitive encounters included anthozoan cnidarians, ascidians, calcareous tube-dwelling polychaetes, calcarean sponges and demosponges, cirriped crustaceans (barnacles), and cheilostome and cyclostome bryozoans. A maximum of 7 of these taxa were recorded in any single replicate in competition with all others. Like transitivity, the number of taxa involved in competition showed little and non-significant variability between time periods but was significantly different in space (Table $2 b$, e.g. region factor, $F_{2}=113.45, \mathrm{p}<0.001$ ). Although there was comparatively more variation than in transitivity, all regression lines were similarly non-significantly different from a zero slope (Fig. 3). Thus, with respect to the number of taxa involved in competition, the null hypothesis that the number of taxa does not change with time cannot be rejected for coastal boulder communities on the time-scale of this study.

The proportion of interspecific (compared to intraspecific) competition varied considerably (by 21 to
Table 2. Example of GLM ANOVA testing (a) transitivity, (b) number of taxa involved in competition and (c) proportion of interspecific competition between time periods, sites and regions. No $F$ ratio for time $\times$ site (region) for transitivity because of missing data. Region and site interactions were significant and are shown in bold

\begin{tabular}{|c|c|c|c|c|}
\hline Source & $\mathrm{df}$ & MS & $F$ & $\mathrm{p}$ \\
\hline \multicolumn{5}{|c|}{ (a) Transitivity (hierarchisation) } \\
\hline Region & 2 & 0.5413 & 20.74 & 0.004 \\
\hline Site (Region) & 5 & 0.0260 & 44.48 & 0.000 \\
\hline Time & 3 & 0.0006 & 0.95 & 0.420 \\
\hline Region $\times$ Time & 6 & 0.0001 & 0.24 & 0.961 \\
\hline Time $\times$ Site (Region) & 14 & 0.0030 & & \\
\hline Error & 61 & 0.0065 & & \\
\hline Total & 91 & & & \\
\hline \multicolumn{5}{|c|}{ (b) No. of taxa involved in competition } \\
\hline Region & 2 & 31.4236 & 114.79 & 0.000 \\
\hline Site (Region) & 5 & 1.3188 & 12.45 & 0.000 \\
\hline Time & 3 & 0.1277 & 0.47 & 0.712 \\
\hline Region $\times$ Time & 6 & 0.2736 & 2.62 & 0.062 \\
\hline Time × Site (Region) & 15 & 0.1049 & 0.18 & 1.000 \\
\hline Error & 63 & 0.5794 & & \\
\hline Total & 94 & & & \\
\hline \multicolumn{5}{|c|}{ (c) Proportion of interspecific competition } \\
\hline Region & 2 & 19504.3 & 8175.20 & 0.000 \\
\hline Site (Region) & 5 & 1049.7 & 85.25 & 0.000 \\
\hline Time & 3 & 6.2 & 2.42 & 0.149 \\
\hline Region $\times$ Time & 6 & 2.4 & 0.19 & 0.974 \\
\hline Time × Site (Region) & 15 & 12.3 & 0.54 & 0.910 \\
\hline Error & 63 & 22.9 & & \\
\hline Total & 94 & & & \\
\hline
\end{tabular}

$95 \%$ ). No such levels of variability were apparent (in arcsine-transformed data) between time periods, but again regions and sites were highly significantly different (Table 2c). As for transitivity and the numbers of taxa involved in competition, regressions of the interspecific proportion of competition with time did not significantly differ from a zero slope (Fig. 4). Thus the third null hypothesis could not be rejected with respect to the final measure studied (the prevalence of interspecific competition), for coastal boulder communities on the time-scale of this study.

\section{DISCUSSION}

As ecologists do today, Darwin (1859) considered that the importance of competition clearly varies in time and space; yet in some ways little progress has been made in elucidating this further. As in the current study, many investigations of marine competition over the past 50 yr have focused on interference-competition for space. Studies of interference-competition at single localities have demonstrated the extent of temporal variability along ecological (Sebens 1986, Chor- 


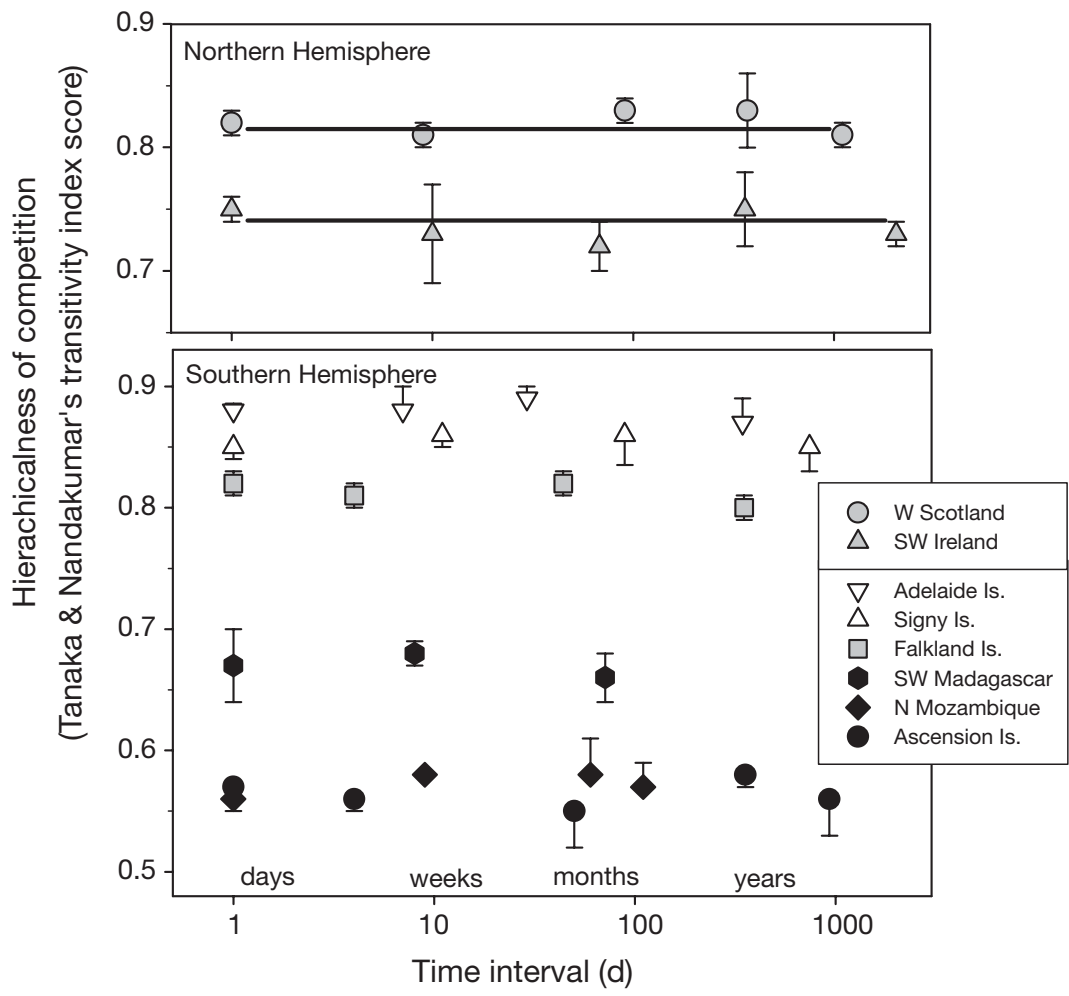

Fig. 2. Degree of hierarchicalness (transitivity) in competition as a function of time interval between samples and study region. Transitivity measured using Tanaka \& Nandakumar's (1994) index (whereby 0: entirely tied outcomes and 1 = increasing hierarchicalness of sample). Data are mean $\pm \mathrm{SE}(\mathrm{n}=3)$; zeroslope regression lines are shown in upper (Northern Hemisphere) plot. Regressions for all study sites were non-significantly different from zero

other measures) are reasonably similar to those found in the voluminous literature on point-in-time studies when results are compared for similar geographic regions. For example, in the current study, the Tanaka \& Nandakumar's (1994) index was typically $\sim 0.83$ for the Falkland Islands, compared to 0.88 found by Lopez Gappa (1989) in nearby Patagonia. Over short timescales, Sebens (1986) and Chornesky (1989) reported stronger variability in the outcomes of interference-competition than that found here, although the latter study focused entirely on corals. Variability in the values for each aspect of interference-competition over the time period of the current study in most cases ranged from about 10 to $20 \%$ (Figs. 3, 4 \& 5), similar to levels found by McKinney (1995) over tens of million of years ago in bryozoans. Whilst it could be considered unreasonable to scale-up from years (the maximum time-scales in the current study) to geological time periods, the current results do suggest repeatability over ecological time-scales. Whether or not it is valid to state that there are strong differences in the nature of competition from the poles to the tropics uncomplicated by

nesky 1989) or evolutionary (McKinney 1995) timescales, but have offered little spatial data. In contrast, other studies of interference-competition have revealed wide spatial-scale patterns (Barnes 2002). There is a huge literature on point-in-time studies (e.g. Connell 1961a, Dayton 1971, Jackson 1979, Quinn 1982, Russ 1982, Todd \& Turner 1988, Tanaka \& Nandakumar 1994, Barnes \& Dick 2000) that has shown levels of interference-competition transitivity or other aspects at a particular place and time. What has not been investigated is the spatial situation weeks or months later. To interpret this extensive literature, as across ecology (e.g. see Levin 1992, Karlson et al. 2004) scale issues (in time and space) must be considered. This would be difficult using fossil evidence, but is possible over brief ecological time-scales across modern environments. The current study has attempted this using marine encrusting communities as model taxa and coastal boulder fields as a model environment. Over the time-scales investigated here (days to years), significant temporal variability (in the 3 measures chosen) at the community level was not detected in any study region ( $p>0.05$ with time as a factor in all GLM ANOVAs). The absolute values of transitivity (and small-scale spatial or temporal factors depends on the strengths and weaknesses of the current study.

First, the present study focused at the community level on boulders. It is known that there can be considerable changes at the individual, or even individual species, level in competition over ecological timescales (Paine 1974, Sebens 1986, Chornesky 1989, Karlson 1999). At smaller scales of time and space, Sousa (1979) and others have demonstrated that boulder communities (as studied here) comprise many different successional states due to differential levels of stability/disturbance. Although individual boulder assemblages are likely to be far from equilibriate, the sample size in the current study was considerable, and the relative constancy of the results reported herein would suggest that our sample size was sufficiently large to override small-scale space and time variability. However, Jackson et al. (2001) have shown that major changes occur (in the context of anthropogenic influences) in other coastal communities on longer ecological time-scales. Such effects are likely to change the outcome of interference-competition through altering the entire food web and composition of communities. 


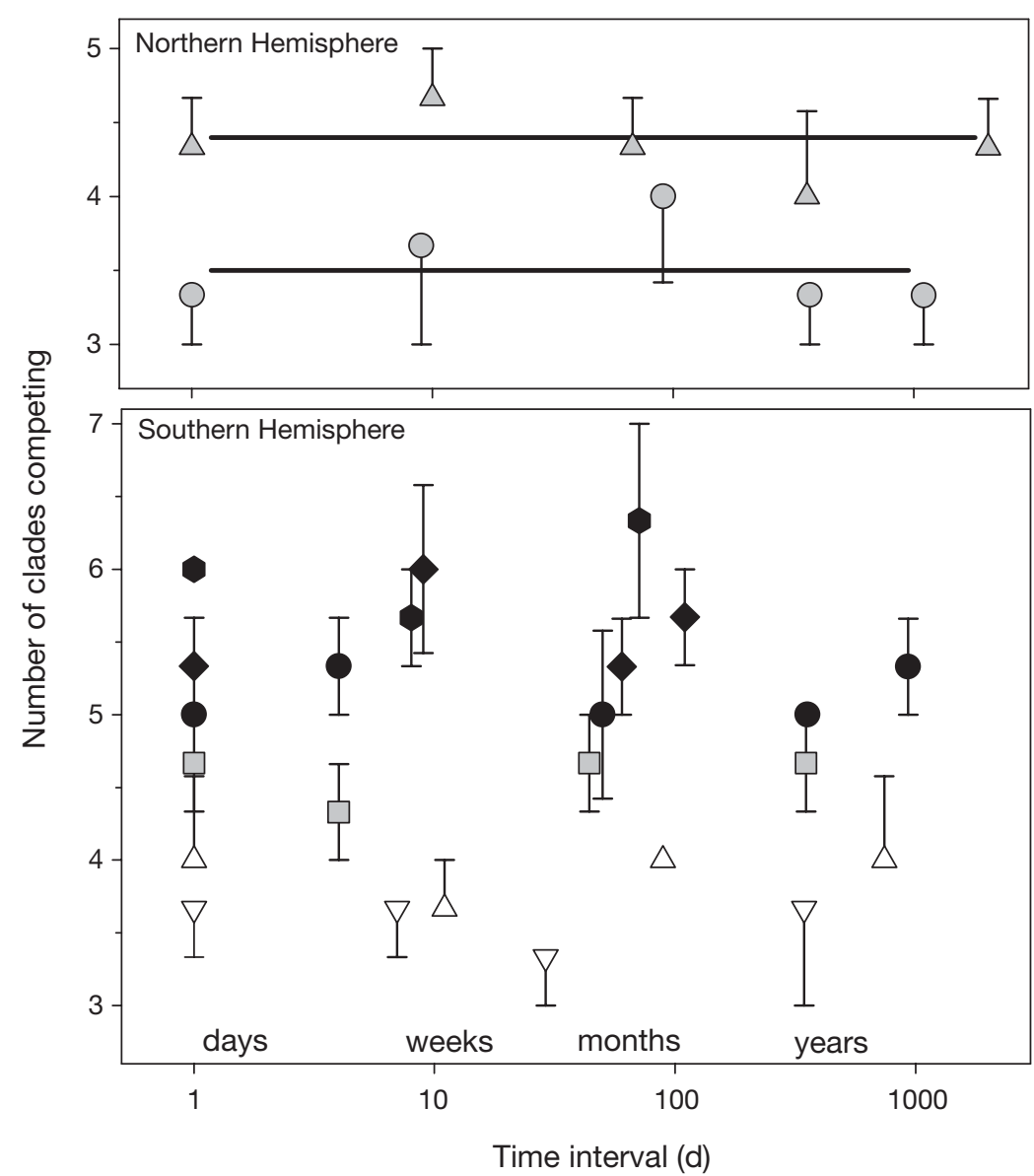

Fig. 3. Number of competitor taxa involved in competition as a function of time interval between samples and study region. Data, regressions and key to symbols as in Fig. 2

Second, the principal focus of the Jackson et al. (2001) study was on the wide-scale reduction of higher predators (by man). The present study did not consider predation as a factor in the model taxa and habitats covered, yet there is a wide literature reporting strong potential influences of predators on aspects of competition (Connell 1961a, Paine 1966, 1974, Sousa 1979, Menge \& Sutherland 1987). The problem is that although direct predation influences on competition has been demonstrated for a few keystone species, the effect of most predators in most localities is inferred (often probably incorrectly, see Elner \& Vadas 1990) or unknown. For none of the localities in the present study was there literature showing that any predator directly influenced competition, and to examine this aspect would have been impractical within the time, logistical or design constraints of this study. Nevertheless, within the time-scales considered, the constancy of results would suggest that within-site predation effects are either also fairly constant from days to years or are relatively negligible.
Third, body size or growth rate were potentially important variables unconsidered in the current study. Both are complex factors. Many 3-dimensional organisms such as ascidians and mussels are strong competitors for space (compared with encrusting 2-dimensional species), but others such as brachiopods are not (see Paine 1974, Jackson 1979, Barnes \& Dick 2000). Amongst the strongest and weakest interference competitors within the major taxa, some can have similar growth rates (see Stanwell-Smith \& Barnes 1997). Barnes (2003) examined the outcomes (in interference-competition) of many of the species from the same model taxa and 2 of the sites used in the current study, with respect to competitor-relatedness, and reported that overall interactions had similar outcomes when any 2 competitors were more distantly related than confamilial, regardless of body size or growth rate. Both this and the constancy of the within-site between-times results reported here suggest that body size and growth rate are not dominant factors at the scales considered in the current study.

Fourth, the structure or outcomes of interference-competition can be measured in many ways. This study examined only 3 of these, but some robustness of the findings is indicated by the fact that all 3 measures gave similar results.

Finally, a strength of the study was that, although from a range of taxa, all model organisms were essentially at a similar trophic level and were mostly suspension-feeders (except for anemones). However, in shallow waters, there are competitors at other trophic levels, most obviously algae. Had the upper surfaces of the boulders been included, then algae would have been in most cases the major space occupiers (author's pers. obs.). Although there is a large literature on both marine and terrestrial land plant-animal interactions, this is not discussed here as it introduces complexities of trophic level and others such as light regime.

Despite some potentially important factors not being measured, the findings of the current study seem robust. An important implication is that single point-intime studies do seem to reasonably represent competition in similar communities. This potentially makes the large literature on modern competition much more useful in meta-analysis or other comparative methods 


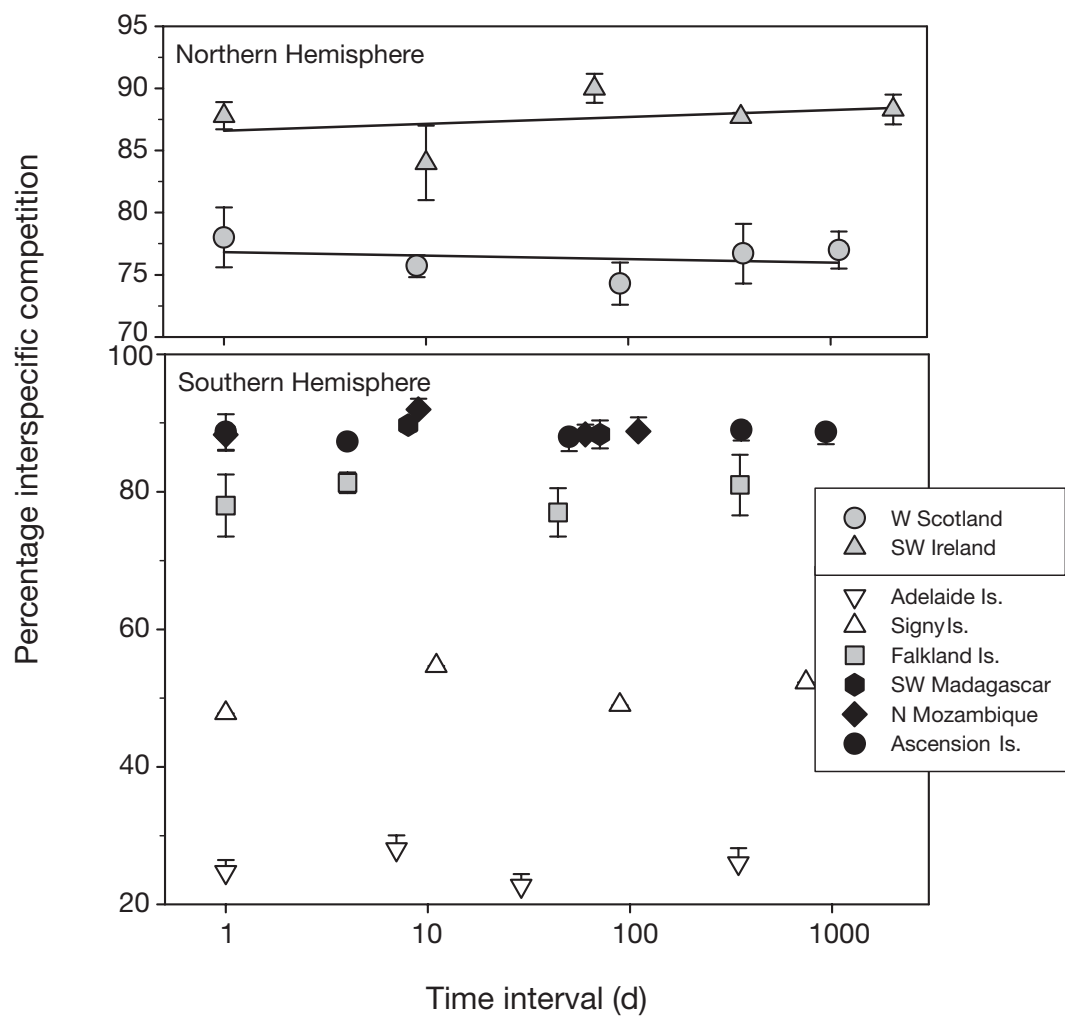

Fig. 4. Proportion of interspecific interactions in competition as a function of time interval between samples and study region. Data, regressions and key to symbols as in Fig. 2

(assuming commonality of protocol) to evaluate aspects of competition across scales (see Connell 1983, Gurevitch et al. 1992, Englund et al. 1999, Osenberg et al. 1999, Barnes 2002).

Thus, if this study supports the validity of large-scale spatial patterns in competition (see Barnes 2002, Barnes \& Kuklinski 2005), does this aid in interpreting studies (e.g. McKinney 1995) on large-scale temporal patterns? Unfortunately, this is not clear. Data across locations (or perhaps more importantly, environments) are needed. Intuitively, there are periods and places when and where competition is likely to have been much more important than others. For example, highlatitude marine communities have been repeatedly pushed to the edge of continental shelves by glacial maxima in the last few tens to hundreds of kyr, and those that survived living on the edge of the shelf mostly repopulated shallow-shelf environments (see Elverhoi 1984, Brey et al. 1996). For some communities, space could have been $<2 \%$ of that available now and it seems likely that competition for resources was intense. Demonstration of any such 'ghost of competition past' (Connell 1980) has proved exceptionally difficult. In the examples given, the nature of ice-shelf movement tends to obliterate evidence of organisms, let alone competition. Even in modern time, competi- tion has not been demonstrated for most taxa in most aquatic environments or for many limiting resources (but see Connell 1983, Hochberg \& Lawton 1990, Gurevitch et al. 1992, Osenberg et al. 1999).

The current study has shown that the strong differences observed in competition between hard-substrate encrusters of different regions is not confounded by temporal considerations (up to the scale of years). This leads to 2 questions: (1) why is there such relative constancy in measures of competition within regions? (2) why are there differences between regions? With regard to the first question, it would seem that the dynamism reported on local scales in settlement and recruitment timing, predation and other factors actually makes relatively little difference to overall measures of interference-competition, at least for the measures used here. It is harder to explain why interferencecompetition at high latitude should be so different from that at low latitude, since so many factors vary. In contrast to the tropics, shallow marine communities at high latitude are subject to highly seasonal light climate, food and disturbance, and have regularly (on the scale of thousands of years) reinvaded continental shelves following the retreat of ice shelves (Arntz et al. 1994). One potential explanation is that at lower latitude, there is a much stronger selection pressure for species able to avoid competitive exclusion, leading to networks whereby most species can win interactions against any competitor some of the time (Petraitis 1979, Russ 1982, Chornesky 1989). Such communities have existed in relatively constant conditions and in regular competition with similar sets of competitors for a considerable time (McKinney 1995). In contrast, it is not obvious that the survival of any polar encrusting species depends on avoiding overgrowth: even the poorest overgrowth competitors can be abundant (see Barnes \& Kuklinski 2005), as wave action and ice scour constantly create new space on small scales and fluctuating ice sheets on larger scales. Under regimes of expanding and retreating iceshelves the selection pressures have been and are very different at higher latitudes; development mode and eurybathy would be more important to a species persistence than competitive ability (Brey et al. 1996, Aronson \& Blake 2001, Poulin et al. 2002). There are other potential explanations for why the outcome of interference-competition should differ between low 
and high latitudes: at lower latitudes, competitors would include many representatives of some taxa and fewer of others; there would be more competitors with specific light-intensity (for symbionts) preferences and continuous competition/growth throughout the year. The most crucial result of the current study, however, is the demonstration that differences in interferencecompetition across space are robust across ecological time-scales.

Acknowledgements. The author thanks Peter Rothery for statistical advice, and Professors Lloyd Peck, Steven Chown and 3 anonymous referees for constructive comments leading to a much improved manuscript.

\section{LITERATURE CITED}

Arntz WE, Brey T, Gallardo VA (1994) Antarctic zoobenthos. Oceanogr Mar Biol Annu Rev 32:241-304

Aronson RB, Blake DB (2001) Global climate change and the origin of modern benthic communities in Antarctica. Am Zool 41:27-39

Barnes DKA (2002) Polarisation of competition increases with latitude. Proc R Soc Lond B 269:2061-2069

Barnes DKA (2003) Competition asymmetry with taxon divergence. Proc R Soc Lond B 270:557-562

Barnes DKA, Arnold RJ (2001) A growth cline in encrusting benthos with latitude within Antarctic waters. Mar Ecol Prog Ser 210:85-91

Barnes DKA, Dick MA (2000) Overgrowth competition between clades: implications for interpretation of the fossil record and overgrowth indices. Biol Bull (Woods Hole) 199:85-94

Barnes DKA, Kuklinski P (2005) Bipolar patterns of intraspecific competition in bryozoans. Mar Ecol Prog Ser 285:75-87

Brey T, Dahm C, Gorny M, Klages M, Stiller M, Arntz WE (1996) Do Antarctic benthic invertebrates show an extended level of eurybathy? Antarct Sci 8:3-6

Brown JH, Davidson DW (1979) An experimental study of competition between seed eating desert rodents and ants. Am Zool 19:1129-1145

Chornesky EA (1989) Repeated reversals during spatial competition between corals. Ecology 70:843-855

Connell JH (1961a) Effects of competition, predation by Thais lapillus and other factors on natural populations of the barnacle Balanus balanoides. Ecol Monogr 31:61-104

Connell JH (1961b) The influence of interspecific competition and other factors on the distribution of the barnacle Chthamalus stellatus. Ecology 42:710-723

Connell JH (1980) Diversity and the coevolution of competitors, or the ghost of competition past. Oikos 35:131-138

Connell JH (1983) On the prevalence and relative importance of interspecific competition: evidence from field experiments. Am Nat 122:661-696

Darwin C (1859) On the origin of species. Murray, London

Dayton PK (1971) Competition, disturbance and community organisation: the provision and subsequent utilisation of space in a rocky intertidal community. Ecol Monogr 41: 351-389

Elner RW, Vadas RL (1990) Inference in ecology: The sea urchin phenomenon in the Northwestern Atlantic. Am Nat 136:108-125

Elverhoi A (1984) Glaciogenic and associated marine sediments in the Weddell Sea, Fjords of Spitsbergen and the
Barents Sea: a review. Mar Geol 57:53-88

Englund G, Sarnell O, Cooper SD (1999) The importance of data-selection criteria: meta-analyses of stream predation experiments-meta-analysis in ecology. Ecology 80: $1132-1141$

Giangrande A, Licciano M (2004) Factors influencing latitudinal pattern of biodiversity: an example using Sabellidae (Annelida, Polychaeta). Biodiv Evol 13:1633-1646

Grosberg RK (1981) Competitive ability influences habitat choice in marine invertebrates. Nature 290:700-702

Gurevitch J, Morrow LL, Wallace A, Walsh JS (1992) A metaanalysis of competition in field experiments. Am Nat 140: 539-572

Hochberg ME, Lawton JH (1990) Competition between kingdoms. Trends Ecol Evol 5:367-370

Jackson JBC (1979) Morphological strategies of sessile animals. In: Larwood G, Rosen BR (eds) Biology and systematics of colonial organisms. Academic Press, London, p 499-555

Jackson JBC, Kirby MX, Berger WH, Bjorndal KA and 14 others (2001) Historical overfishing and the recent collapse of coastal ecosystems. Science 293:629-638

Karlson RH (1999) Dynamics of coral communities. Kluwer Academic, Dordrecht

Karlson RH, Cornell HV, Hughes TP (2004) Coral communities are regionally enriched along an oceanic biodiversity gradient. Nature 429:867-700

Levin SA (1992) The problem of pattern and scale in ecology. Ecology 73:1943-1967

Lidgard S, McKinney FK, Taylor PD (1993) Competition, clade replacement, and a history of cyclostome and cheilostome broyozoan diversity. Paleobiology 19:352-371

Lopez Gappa JJ (1989) Overgrowth competition in an assemblage of encrusting bryozoans settled on artificial substrata. Mar Ecol Prog Ser 51:121-130

McKinney FK (1995) One hundred million years of competitive interactions between bryozoan clades: asymmetrical but not escalating. Biol J Linn Soc 56:465-481

McKinney FK, Lidgard S, Sepkoski JJ, Taylor PD (1998) Decoupled temporal patterns of evolution and ecology in two post-Paleozoic clades. Science 281:807-809

Menge BA, Sutherland JP (1987) Community regulation: variation in disturbance, competition and predation in relation to environmental stress and recruitment. Am Nat 130: $730-757$

Osenberg CW, Sarnelle O, Cooper SD, Holt RD (1999) Resolving ecological questions through meta analysis: goals, metrics, and models. Ecology 80:1105-1117

Paine RT (1966) Food web complexity and species diversity. Am Nat 100:65-75

Paine RT (1974) Intertidal community structure: experimental studies on the relationship between a dominant competitor and its principal predator. Oecologia 15:710-719

Petraitis PS (1979) Competitive networks and measures of intransitivity. Am Nat 114:921-925

Poulin E, Palma AT, Feral JP (2002) Evolutionary versus ecological success in Antarctic benthic invertebrates. Trends Ecol Evol 17:218-222

Quinn JF (1982) Competitive hierarchies in marine benthic communities. Oecologia 54:129-135

Rubin JA (1982) The degree of intransitivity and its measurement in an assemblage of encrusting cheilostome Bryozoa. J Exp Mar Biol Ecol 60:119-128

Russ GR (1982) Overgrowth in a marine epifaunal community: competitive hierarchies and competitive networks Oecologia 53:12-19

Schluter D (1986) Character displacement between distantly 
related taxa? Finches and bees in the Galápagos. Am Nat 127:95-102

Sebens KP (1986) Spatial relationships among encrusting marine organisms in the New England subtidal zone. Ecol Monogr 56:73-96

Sepkoski JJ (1996) Competition in macroevolution: the double wedge revisited. In: Jablonski D, Erwin DH, Lipps JH (eds) Evolutionary paleobiology. University of Chicago Press, Chicago, IL, p 211-255

Sousa W (1979) Experimental investigation of disturbance and ecological succession in a rocky intertidal algal community. Ecol Monogr 49:227-254

Stanwell-Smith D, Barnes DKA (1997) Benthic community development in Antarctica: recruitment and growth on settlement panels at Signy Island. J Exp Mar Biol Ecol 212: 61-79

Stehli FG, Wells JW (1971) Diversity and age patterns in hermatypic corals. Syst Zool 20:115-126

Editorial responsibility: Howard I. Browman (Associate Editor-in-Chief), Storebø, Norway
Tanaka M, Nandakumar K (1994) Measurement of the degree of intransitivity in a community of sessile organisms. J Exp Mar Biol Ecol 182:85-95

Taylor PD, Wilson MA (2003) Palaeoecology and evolution of marine hard substrate communities. Earth-Sci Rev 62: $1-103$

Todd CD, Turner SJ (1988) Ecology of sublittoral cryptic epifaunal assemblages. II. Non-lethal overgrowth of encrusting bryozoans by colonial ascidians. J Exp Mar Biol Ecol 74:113-126

van Soest RWM (1994) Distribution of recent Hexactinellida. In: van Soest R, van Kempen TMG, Braekman JC (eds) Sponges in time and space. Balkema, Rotterdam, p 213-224

Witman JD, Etter RJ, Smith F (2004) The relationship between regional and local species diversity in marine benthic communities: a global perspective. Proc Natl Acad Sci 101: 15664-15669

Submitted: May 19, 2005; Accepted: September 20, 2005 Proofs received from author(s): April 25, 2006 